\title{
CSR as Reputation Insurance: Primum Non Nocere
}

\section{Citation}

Minor, Dylan B., and John Morgan. "CSR as Reputation Insurance: Primum Non Nocere." California Management Review 53, no. 3 (Spring 2011): 40-59.

\section{Published Version}

http://cmr.ucpress.edu/content/53/3/4

\section{Permanent link}

http://nrs.harvard.edu/urn-3:HUL.InstRepos:22836595

\section{Terms of Use}

This article was downloaded from Harvard University's DASH repository, and is made available under the terms and conditions applicable to Other Posted Material, as set forth at http:// nrs.harvard.edu/urn-3:HUL.InstRepos:dash.current.terms-of-use\#LAA

\section{Share Your Story}

The Harvard community has made this article openly available.

Please share how this access benefits you. Submit a story.

Accessibility 


\title{
CSR as Reputation Insurance:
}

Primum Non Nocere

\author{
By \\ Dylan Minor \\ University of California, Berkeley \\ And \\ John Morgan \\ University of California, Berkeley and Yahoo
}

\begin{abstract}
We provide a theoretical framework showing how CSR activities can insure a firm against lost reputation in the face of adverse events. We offer evidence for this linkage through a case study and a multi-year analysis of stock price responses for S\&P 500 companies following product recalls. We find that firms with better CSR ratings fare better than those that do not. Furthermore, a firm that is exceptional in both doing good and avoiding harm suffers virtually no reputational damage following events. Using the results of the study, we offer a guide to managers for determining the appropriate amount and mix of CSR to undertake.
\end{abstract}

Keywords: Corporate social responsibility, reputation, insurance 


\section{Introduction}

For many firms, the most precious asset, the key to sustainable competitive advantage, lies not on their balance sheet nor in the human capital of their workforce, rather it is their reputation. For instance, IBM's reputation for being an enterprise friendly and efficient solutions provider has enabled it to beat rivals for business over many years. McDonald's reputation for being a family friendly and economical place to eat has sustained its market share in the face of fierce competition from other chains.

But reputation can be a fragile thing. Toyota, who became the largest automobile manufacturer through its reputation for reliability and value, has suffered grievously as allegations of faulty accelerators and cover-ups of these problems have come to light. This can be seen vividly in the resale market where even Toyota vehicles unaffected by the recalls declined in value, predicted ultimately to be some 4-5\%. ${ }^{1}$ Likewise Dell, who became the leading PC manufacturer largely on the basis of quality and low price, has suffered reverses in recent years owing to incidents of laptop batteries catching fire and other quality control problems, contributing to the firm's cumulative loss of a third of its market value. ${ }^{2}$ In short, reputational risk is one of the key business risks that firms face.

The correct response to business risk is to turn to insurance markets or to self-insure. For instance, Google, whose reputation rests on the reliability and speed of its search results, takes the unusual step of designing its own servers with special features such as a patented internal backup power system to maximize reliability and efficiency should a problem arise. ${ }^{3}$ Manufacturers who are dependent on key raw materials will routinely use futures markets to hedge price risk. Multinationals will likewise turn to currency markets to hedge exchange rate risk. But there is no obvious market for firms seeking to insure against reputation risk.

In this paper, we will argue that a firm's corporate social responsibility (hereafter CSR) activities have the effect of providing partial self-insurance against reputation risk. To support this claim, we first 
briefly sketch a theory showing the link between CSR and a firm's reputation. Next, we illustrate this channel using a case study showing stock price reactions to adverse events experienced by Boston Scientific and Guidant in the medical stent market. While the case study is helpful, it is by no means definitive. To examine the mechanism more broadly, we conduct a study of the link between reputation and CSR for all S\&P 500 companies over the period 1991-2006. Our main finding here is that stock price response (which we use as a proxy for a firm's reputation), declines significantly less following an adverse event (a product recall), when a firm is engaging in CSR than when it is not.

Our study also reveals a key additional insight: While CSR is often thought of as visible "doing good" activities, such as charitable contributions, a less visible side, "not doing harm," proves equally important. In particular, we find a synergistic effect on reputation for firms who are exceptional both in doing good and avoiding harm. Perhaps more surprising is that a disharmonious strategy, doing good while also doing harm, leads to reputational consequences that are worse than simply doing nothing at all. For managers, these findings have two key implications: First, even though not doing harm is less visible, it should not be neglected as a CSR lever. Second, and perhaps more important, "bad" behavior in one aspect of a firm's operations cannot be erased by "good" behavior in another. CSR as reputation insurance only works when a firm is consistent in its application.

\section{How CSR Acts as Reputation Insurance}

Firms face a variety of business risks in today's dynamic environment. A key consideration for firms is how best to manage or hedge these risks. Here we describe how CSR activities can play an important role in the risk-management dimension of a firm's strategy. Consider the situation of Mattel in 2007. ${ }^{4}$ Mattel 's CEO, Robert A. Eckert, had just learned that it faced the largest toy recall in history, covering some of its most popular product lines. These toys were found to contain extremely high levels of lead paint. Disclosing the problem and recalling the affected toys would surely be costly to Mattel; 
however the long-run impact on the profitability of the firm would ultimately depend on the cause that the public and investors ascribed to the problem. If they saw the problem as one mainly stemming from Mattel's negligence in overseeing its Chinese suppliers, there would be serious, long-term consequences. If, however, it were seen as merely an "honest mistake" - something that could happen to even a diligent firm —-the damage would be much less. We shall argue that Mattel's "reputation," driven in part by its perception as a "responsible" corporate citizen, will do much to drive beliefs about the proximate cause of an adverse event.

Although adverse events have direct costs in the form of regulation penalties and lawsuits, there are also indirect costs to consider. For example, Mattel may have to monitor its input suppliers more carefully and engage in a substantial public relation campaigns to communicate such improvements. Being a publicly held company, these expected costs will be (almost) immediately reflected in its stock price. Investors will also price in the future expected cost of such adverse event for the firm---their beliefs about the possibility of such events happening again. Obviously, investors' judgment about this risk will be colored by the firm's reputation before the event. Is this an anomaly or is it consistent with a view that Mattel has been rather cavalier in monitoring its suppliers? In short, the degree of price change following the event will be based on the weight investors place on its cause.

Similarly, regulators have limited resources to investigate adverse events. In local law enforcement, the decision to prosecute some crimes and not others is known as "prosecutorial discretion." In a regulatory setting, a similar principle applies: All things equal, those firms that are thought less likely to have committed negligence as opposed to have experienced bad luck will be pursued less fiercely or not at all.

One can think of a scale describing the possible causes of an incident. The left side of the scale is labeled "bad luck" - the incident was caused by factors largely out of the firm's control. The right side of 
the scale is labeled "bad management" - the incident was caused by negligence, foolhardy cost-cutting, or some other factor under the control of the firm. Where investors and regulators place an event on this scale depends on the firm's reputation, based on its past actions as a "responsible corporate citizen," leading up to the event.

[image 1 here]

Viewed in this light, expenditures on corporate social responsibility (CSR) can be thought of as an insurance premium. In normal times, this simply reflects a pure cost; however, when an incident arises, the firm is insured to the extent that its past CSR activities tip the scale toward bad luck rather than bad management, saving the firm money, avoiding regulatory scrutiny, and preserving the value of its brand. That is, CSR provides a contingent benefit.

The returns from CSR have been much studied by academics. ${ }^{5}$ The typical conclusion of these studies is that returns from CSR are low or even negative. However, these studies focus on returns to CSR during "normal" times-i.e. most of the time. When viewed through an insurance lens, however, our study offers the opposite conclusion-CSR (done correctly) produces considerable returns.

The following analogy shows how one may easily reconcile our results with those of existing studies. Imagine one were interested in studying the returns to purchasing earthquake insurance. A dataset consisting of premiums versus claims in San Francisco over the last 10 years would conclude (correctly) that it is a terrible investment-insurance is a pure cost in "normal" times. The scope of this hypothetical study is too narrow to capture the benefits of earthquake insurance. Such is the case with many CSR studies as well. By focusing on "events" rather than on normal times, we observe a very different story about the value of CSR.

\section{Two CSR Levers: Doing Good and Avoiding Harm}


In building a reputation as a responsible corporate citizen, a firm has two levers at its disposal. First is the positive lever of CSR. That is, the firm can be involved in activities that contribute to the sense the firm "does the right thing." Examples of this are everything from investing in local community services to treating employees extraordinarily well. Second is the lever of avoiding negative CSR. Examples of negative CSR include employing (or buying from supplier who employs) slave labor, engaging in farming or mining in an environmentally unfriendly way, or driving impossibly hard bargains with suppliers or workers that leave it impossible for them to earn a living wage.

\subsection{Which lever to pull?}

The bulk of advice and publicity in CSR activities centers on doing good, but avoiding harm also plays a key role in determining where the balance of responsibility lies following an incident. Partially this stems from the fact that "doing good" activities are more visible and easily measured. For instance, a firm's charitable contributions are readily quantified. In contrast, the costs from avoiding harm activities are actually opportunity costs and, as a result, far more difficult to quantify. For instance, the cost to a firm of not buying from the cheapest supplier because of that supplier's labor practices is the cost difference between using that supplier and the second-best alternative. This cost never appears on a firm's income statement, nor does the CEO appear in the local paper for its supplier decisions.

While the costs of avoiding harm are more difficult to measure and convey to various stakeholders, the benefits may be greater than an equivalent amount of doing good activities. Doing good communicates indirectly to shareholders that adverse events stem from bad luck rather than bad management. But the connection is far from perfect-bad managers can easily pool with good ones by merely imitating and publicizing doing good activities. In contrast, avoiding harm activities are harder for bad managers to imitate. In the example above, a manager would have to investigate the labor practices 
of suppliers, find alternatives, and continue to be vigilant thereafter. Thus, the connection between avoiding harm and avoiding the "bad management" label following an event is more direct.

Additionally, it can take years to build "good" reputation but only days or months of "bad" activities to wipe it away. In other words, reputation building seems to be negatively sloping. "Bad" activities are going downhill in their effect of reputation erosion, whereas "good" activities are going uphill to build reputation. Thus, a firm seeking only a neutral reputation (i.e., by trying to limit negative events and activities) may in the end fare better than the firm that instead commits the same resources to "doing good" while neglecting the "avoiding harm" lever. In fact, as firms are increasingly involved in some "good" activities in building positive CSR, the value of doing so diminishes.

In this spirit, we now consider a case study of two firms that generally match one another on the "doing good" dimension but differ in terms of "avoiding harm." As we shall see, the market comes to dramatically different judgments about bad luck versus bad management for the two different firms.

\section{Case Study: Guidant vs. Boston Scientific}

Our case study is not meant to be statistical proof our claims, but rather a helpful illustration of our thesis that CSR acts as reputation insurance. The statistical proof is provided in Section 5, where we study the link between CSR and firm value following an incident based on all S\&P 500 firms over some 16 years.

Guidant and Boston Scientific are (were) publicly traded medical device manufacturers involved in the production of medical stents. Over the past 12 years, both manufacturers have been troubled by numerous stent recalls that ultimately led to regulatory scrutiny. In this case, we study the connections between each firm's CSR activities and the stock price response to news about each stent recall. 
To conduct such a study, we need a measure of CSR activities. Here, we rely on data provided by KLD, which is considered the "gold standard" in reputation research on CSR. ${ }^{6}$ KLD rates firms on several areas of CSR, and both on positive and negative dimension. One such area of rating is product CSR. Product CSR can be thought of as the extent a firm conscientiously manufactures and distributes its products. The positive dimension of such CSR includes providing products to needy individuals, extra quality control of its supply lines, and its product safety. The negative dimension includes events such as being involved in fights with regulators over product safety and unethical marketing campaigns.

KLD rates each dimension on a 0-4 scale, where each integer represents an additional issue being present. Figures 1 and 2 are a time series of each the positive CSR and negative CSR trends for each of our firms on the dimension of product CSR. ${ }^{7}$

[insert figure 1 here]

[insert figure 2 here]

Figure 1 reveals that Boston Scientific (hereafter BSX) had a modest rating of positive CSR (i.e., 1.0) that did not change for the entire series. Meanwhile, Guidant (hereafter GDT) began with no positive CSR rating, matched BSX's rating after one year, and then maintained this same rating until 2005, when its rating again fell to zero. There is little to distinguish the two firms in terms of positive CSR. Figure 2, on the other hand, reveals key differences in the two firms' reputations in terms of "avoiding harm." While both companies suffered erosion of their negative CSR ratings over the course of the study, save for 1997, BSX always had a worse rating than GDT on this dimension.

In 1998 BSX recalled one of their stent products. Rather than punishing the firm, the market reacted positively-BSX enjoyed a $5.54 \%$ positive abnormal return in its stock price in the period immediately following the announcement. ${ }^{8}$ Apparently the market saw the recall as a positive given 
BSX's past reputation. BSX was seen as being vigilant about its products and acting quickly when issues were identified.

When BSX faced a second recall in 1999, the balance of blame seems to have shifted from bad luck to bad management. At this time, BSX's negative CSR rating was firmly in negative territory at -1 . This time, the market's reaction was very different-BSX lost $5.66 \%$ of firm value during the event period. The key point to note here is that, despite enjoying an excellent positive CSR rating, the market still punished BSX.

In 2001, GDT issued a product recall for one of its stents. While its CSR situation was similar to BSX at the time of its first recall, the market's reaction was not. Unlike BSX in 1998, the cumulative effect of recalls led the market to punish GDT, driving share value down by $6.5 \%$ immediately after the announcement.

Meanwhile, both companies continued to neglect the avoiding harm lever, though more so in BSX's case. By 2002, BSX's negative reputation had fallen to -2 while GDT had fallen to -1 . This same year, regulators stepped into the stent market and placed BSX under criminal investigation for its past recalls. GDT, however, was not included in this probe. This same pattern repeats itself in the financial markets. A GDT recall in 2003 resulted in a 3.1\% gain in value while a 2004 BSX recall produced a whopping $18.9 \%$ loss.

The difference in price response to the two levers is illustrated further in 2006. At this point, GDT lags BSX in terms of positive CSR but is ahead in terms of avoiding harm. Both firms make additional product recalls. For BSX, this results in a $12.06 \%$ loss in value while GDT suffers only a $4.9 \%$ drop in value. 
Shortly thereafter BSX purchases GDT. Does this mean that BSX has "bought" GDT's relatively better reputation in the stent market? This remains to be seen. However, what can be seen in this case is the connection between CSR and stock price responses following product recalls. The case also illustrates how this response differs depending on the firm's "stance" in terms of positive and negative CSR. Likewise, it is suggestive of the fact that regulatory scrutiny might also depend on CSR. Of course, the case is only suggestive. There are a variety of other aspects of the stent market and the strategies of the two companies besides CSR that are neglected in the case. Consequently, the next section examines stock price responses to product recalls for all S\&P 500 firms for the period 1991 to 2006 . The key finding to emerge from this study is to highlight that the features of the Guidant v. Boston Scientific case are, in fact, broadly representative.

\section{A Study of CSR, Product Recalls, and Stock Price Response}

To examine the broader case for CSR as reputation insurance, we collected CSR and product recall event data on S\&P 500 firms from 1991 to 2006. As with the case study, we used KLD data as a measure of a firm's CSR activities. We obtained event data through the labor-intensive process of hand collecting product recalls from indices contained in the Wall Street Journal. Though imperfect, the WSJ index has the advantage of providing an objective benchmark for which events to consider. Moreover, omissions will tend to be smaller events, which are likely to be of less importance to firm valuations. These data were then merged with the CRSP database of daily closing stock prices for all S\&P 500 firms; thus allowing us to connect CSR ratings and stock price responses.

Figure 3 shows the annual incidence of product recalls in our sample. As the figure reveals, there were about 15 events per year. This means that each firm in the study had about a $3 \%$ chance of an event each year. Events are "rare" events in the life of a firm, not the normal course of business.

[figure 3 here] 
Figure 4 presents the distribution of stock price returns immediately following events. To compute these returns, as with our case study, we calculate abnormal change in firm value following a recall. This is the change in firm value that cannot be explained as a result of the particular firm's size, capital structure, and relative performance to others. In other words, it is the excess return or loss attributed to the event.

[figure 4 here]

Figure 4 also plots a normal distribution, which is often used as a benchmark for determining if a realized distribution is skewed in a particular manner. The $x$ axis reports cumulative abnormal (event) return. We say cumulative because it is the sum of the return on the day before and the day of the event announcement. We include the day before to account for the possibility of news "leakage" prior to the public announcement. The $y$ axis is the density of a given return level, which is essentially just the frequency of the given return. Notice that the peak of the realized distribution occurs near zero. The market deemed these events as not materially affecting a firm's value. This is not terribly surprising given the breadth of events included in our dataset. For example, one such event is Black \& Decker's announcement of a toaster recall. Obviously, one would not expect this to materially affect the fortunes of Black \& Decker.

A second key, but expected, feature of the data is the skewed "negative" tail of event returns. We would expect that product recalls would more often result in reductions in firm value rather than gains. It is reassuring that this feature is apparent in figure 4.

While KLD grades all firms on a 5 point scale in both the doing good and avoiding harm dimensions of CSR, it is more informative to summarize a firm's CSR rating along each dimension by a binary variable, i.e. a firm can be do good or not and can avoid harm or not. This yields a matrix of four 
possible types of ratings a firm might have as shown in Figure 5. The size of the circles contained in each of the cells of the matrix corresponds to the fraction of firms of each type in our sample.

\section{[figure 5 here]}

The largest number of firms falls into the category of being unexceptional in doing good while strenuously avoiding harm. The next largest category consists of firms that apparently care little about CSR ratings. They are undistinguished on the doing good dimension while being flagged on the harm dimension. A small number of firms are those that are exceptional corporate citizens. They are distinguished on the good dimension while avoiding pitfalls on the harm dimension. Finally, an even smaller number of firms are flagged for doing harm but are apparently trying to compensate for this by also doing good.

While figure 5 describes the CSR of the cross-section of firms, it does not present a picture of changing CSR levels over the period of the study. Figures 6 and 7 highlight CSR trends. Despite the considerable attention given the CSR over the period of the study, we see no material increase in the fraction of firms doing good. Even more surprisingly, the number of firms being rated as doing harm has risen dramatically over this same period.

[figure 6 here]

[figure 7 here]

The trends shown in figures 6 and 7 suggest a change in the mix of firms' CSR strategies, as figure 8 illustrates. Figure 8 reveals that over study period, firms were increasingly abandoning the strategy of avoiding harm. Thus, we see a sharp increase in the number of firms that are undistinguished in the doing good dimension while also flagged in the doing harm dimension. Similarly, we see an increased trend in firms being involved in both good and harmful activities. This small but important 
group grows from about $2 \%$ to $6 \%$ by the end of the series. As will be seen below, this is a very costly strategy.

[figure 8 here]

With this background in mind, we now come to the heart of the study-what is the value to firms of various CSR strategies in terms of reputational insurance. Table 1 presents abnormal stock returns following events for firms pursuing each of the four CSR strategies we outlined above.

[table 1 here]

As a baseline, consider a firm that does not avoid harm nor do good. Such a firm suffers almost a $1 \%$ drop in value following an adverse event. For an S\&P 500 company with an average market capitalization of $\$ 20$ billion, this amounts to $\$ 200$ million in lost value. A firm that avoids doing harm while not distinguishing itself on the good dimension halves this loss. Such firms suffer only a $0.5 \%$ drop in value following an adverse event. Firms that distinguish themselves in both dimensions actually gain about $1.1 \%$ in value following an event. That is, pursuing CSR on both dimensions seems to produce synergistic returns compared to pursuing CSR on only one dimension. Finally, firms that seek to compensate for harm by doing good are punished most severely, losing an average of $2.5 \%$ of value following an event. In terms of our model, doing good alone does not convey a credible signal about a firm's likely negligence associated with an event. If anything, it conveys the opposite signal-good actions are seen as a fig leaf for bad behavior.

While much of the CSR literature focuses on doing good; this may be short-sighted if it leads firms to ignore or underplay the avoiding harm dimension. Indeed, at least in the setting of product recalls, bad marks lead to considerable loss in value; moreover, this effect is magnified if a firm is seen as "compensating" through its actions on the doing good dimension. Thus, any cost-benefit calculation 
must take account of the portfolio of CSR activities. The returns to "doing good" differ greatly depending on a firm's stance in terms of avoiding harm. Likewise, the benefits from avoiding harm are higher in conjunction with distinction on the doing good dimension than when such distinction is absent. In short, avoiding and doing good are complementary activities.

Of course, this is easier said than done. Doing good is fairly straightforward and easily measured. Avoiding harm, however, is harder to "prove" and inherently more subjective. A firm may unwittingly find itself failing to avoid harm despite its best efforts. This suggests the need for a degree of vigilance and managerial skill in the avoiding harm dimension that is considerably more demanding than the doing good dimension, and this should be factored in to the cost-benefit analysis.

\section{Managing CSR Effectively}

When implementing CSR as reputation insurance, there is no simple solution for all firms, even within an industry. Instead, we offer a framework to enable managers to think through the cost-benefit calculus of CSR as reputation insurance.

\subsection{The Nature of the Peril}

As in any actuarial analysis, of fundamental concern is the nature of the peril. That is, what is the magnitude and incidence of events for a firm? This can differ significantly from firm to firm. For instance, a product recall of infant milk formula potentially has a vastly greater effect on firm value than, say, a product recall of a calculator. Thus, the potential cost of events must be assessed. Working from comparable historical events offers a good starting point. In addition to direct costs, a firm must assess the indirect costs of an event. These costs can include everything from the lost production as a result of pulling key management off other projects to deal with the event aftermath to loss of employee morale through bad company publicity. 
Next, the probability of such an event occurring must be estimated. Again, sifting through comparable historical data is a good starting point. Given the paucity of such events and the limited data available, the goal of this exercise should not be to obtain extremely precise estimates, rather, it should be to obtain estimates reflecting the order of magnitude of the peril.

\subsection{The Cost and Effectiveness of Insurance}

The cost and effectiveness of attempting to insure various perils can also vary substantially. Of fundamental concern is the degree to which an adverse event is attributable to bad luck versus bad management. CSR operates by influencing the perception of adverse events in the direction of bad luck. Note, however, that the returns to this influence depend on the base rate attribution. If a firm faces perils that will most certainly be attributed to bad luck regardless of its efforts, then CSR offers little return. For instance, CSR is of no help for events caused by floods or other natural disasters. In contrast, CSR plays a critical role in coloring perceptions of events that would otherwise be viewed as the fault of management. Holding all else constant, the more likely an event is caused by negligence over bad luck, the more payoff CSR insurance can have.

Another consideration is whether CSR activities themselves impact the nature of the peril. Some CSR activity might actually reduce the chance of an adverse event. For example, an energy company that devotes resources to conscientious environmental risk management will also likely experience adverse environmental events less often. Meanwhile, other CSR activities might reduce the magnitude of loss when an event occurs. For example, investing in local communities can build goodwill amongst local customers. If an event happens, these customers may be more likely to give the firm the benefit of the doubt rather than turning to lawyers for redress.

The visibility of CSR activities is also an important consideration. Community investments that are largely invisible offer little reputational benefit. Visibility considerations are not limited to a firm's 
customers, it is also important that these activities be observable by investors and regulators if they are to influence judgment about negligence versus bad luck. When deciding which CSR activities to participate in it is critical to push hard on which activities can be made known, to which stakeholderslarge or small, and the differential cost involved in making such activity known and verifiable.

A firm should also consider which CSR activities it might have a competitive advantage at providing. For example, perhaps a firm already has natural rapport with some local community leaders. In that case, leveraging this "asset" can lower the cost and raise the visibility of CSR activities. Competitive advantage might also be product-based. For instance, a pharmaceuticals firm that manufactures a unique product might donate some fraction of its output to a visible cause.

A firm should also consider peripheral benefits in providing CSR activities, as this reduces the "net" cost of their provision. For example, if a firm's employees are particularly keen on investing in a particular community project, a firm might leverage this enthusiasm by enlisting the help of these employees thus raising morale while reducing costs at the same time. Likewise, peripheral benefits can include increased sales to CSR-valuing customers, improving production processes, innovation, and others.

All these factors then play into an effective cost benefit analysis. Surely it is not a trivial analysis. However, it is essential if one is to formulate a coherent CSR strategy.

\section{Conclusions}

Why should firms engage in CSR activities? Many rationales have been offered with varying degrees of success $^{9}$. Some emphasize the obligations of firms to a broader set of stakeholders; however, fulfilling these obligations may come at the expense of the bottom line. Others suggest that CSR and profit maximization are not at odds, that a firm's CSR activity translates into higher customer willingness to 
pay which the firm is somehow able to capture. One key difficulty with this latter rationale is that it receives little empirical support.

We suggest a new rationale for CSR: It acts as a powerful form of reputation insurance when a firm suffers an adverse event. For firms whose reputation is a key source of competitive advantage, understanding the link between CSR and reputation provides a solution to a "missing markets" problem-how to (partially) insure against reputation risk.

Our multi-year study of S\&P 500 firms offers strong evidence of the link between a firm's CSR activities and its stock price response following an adverse event. When viewed through this lens, decisions about which CSR activities to pursue and how much to pursue them are amenable to costbenefit analyses typical of other forms of insurance. Such a framework is essential if managers seek to intelligently allocate resources in this area.

Our study also revealed the importance of synergies in CSR activities. Firms that harmonize their CSR strategies, both doing good and avoiding harm, are largely immune to reputational damage following adverse events. The same cannot be said for firms pursuing either aspect of CSR alone. Indeed, we find that the disjointed strategy of doing good to compensate for harm produces the greatest damage to a firm's reputation following an event.

We should caution, however, that our study represents a starting point rather than the last word. Our measures of CSR activities are coarse and suffer the same limitations as other studies in this area. An important next step is to develop more granular measures for various aspects of CSR. Our study is limited to product recalls. Of course, one can think of a variety of other events that impact a firm's reputation. In the future, these would be useful to capture and analyze. Finally, we measure reputation in terms of stock price reaction following an event. This measure is only correct to the extent that information about the full impact of the harm is priced. Moreover, it conflates reputational harm with 
the direct cost of making affected parties whole following the event. One could fix this problem to some extent were data on the direct financial costs of adverse events available. 


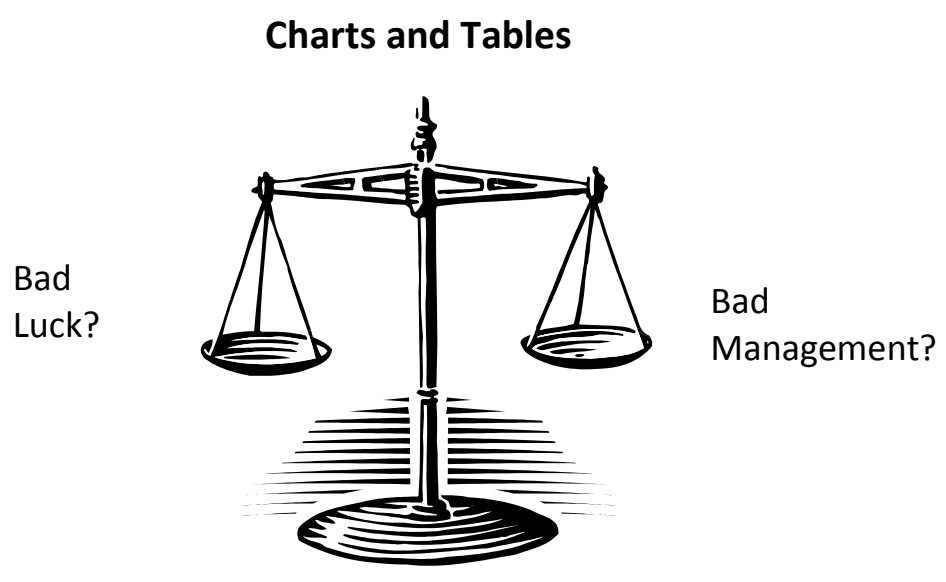

Image 1: Investors and Regulators must Weigh the Chances the Firm had Bad Luck vs. Bad Management

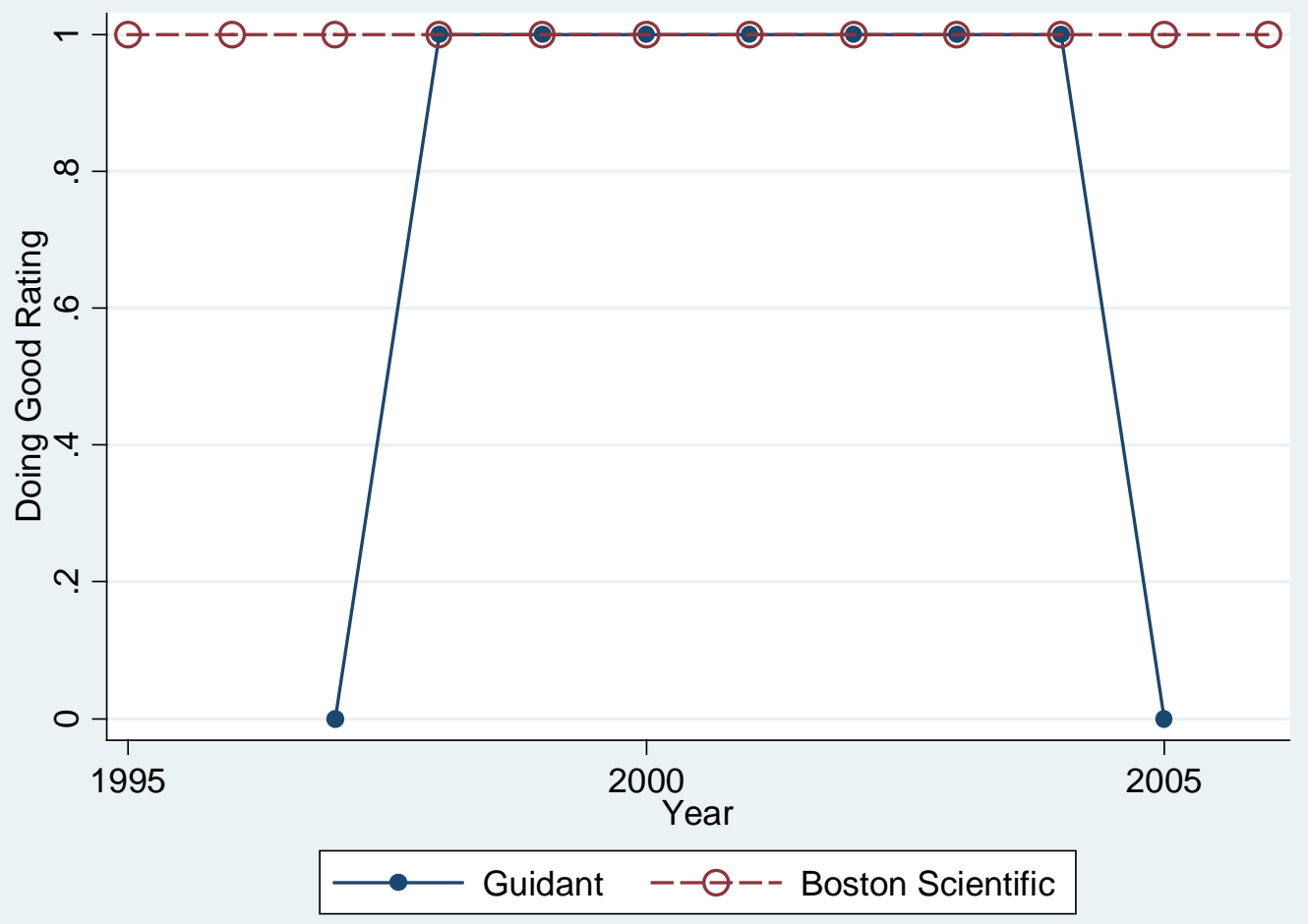

Figure 1: Doing Good Ratings over Time for Guidant and Boston Scientific Source: KLD 


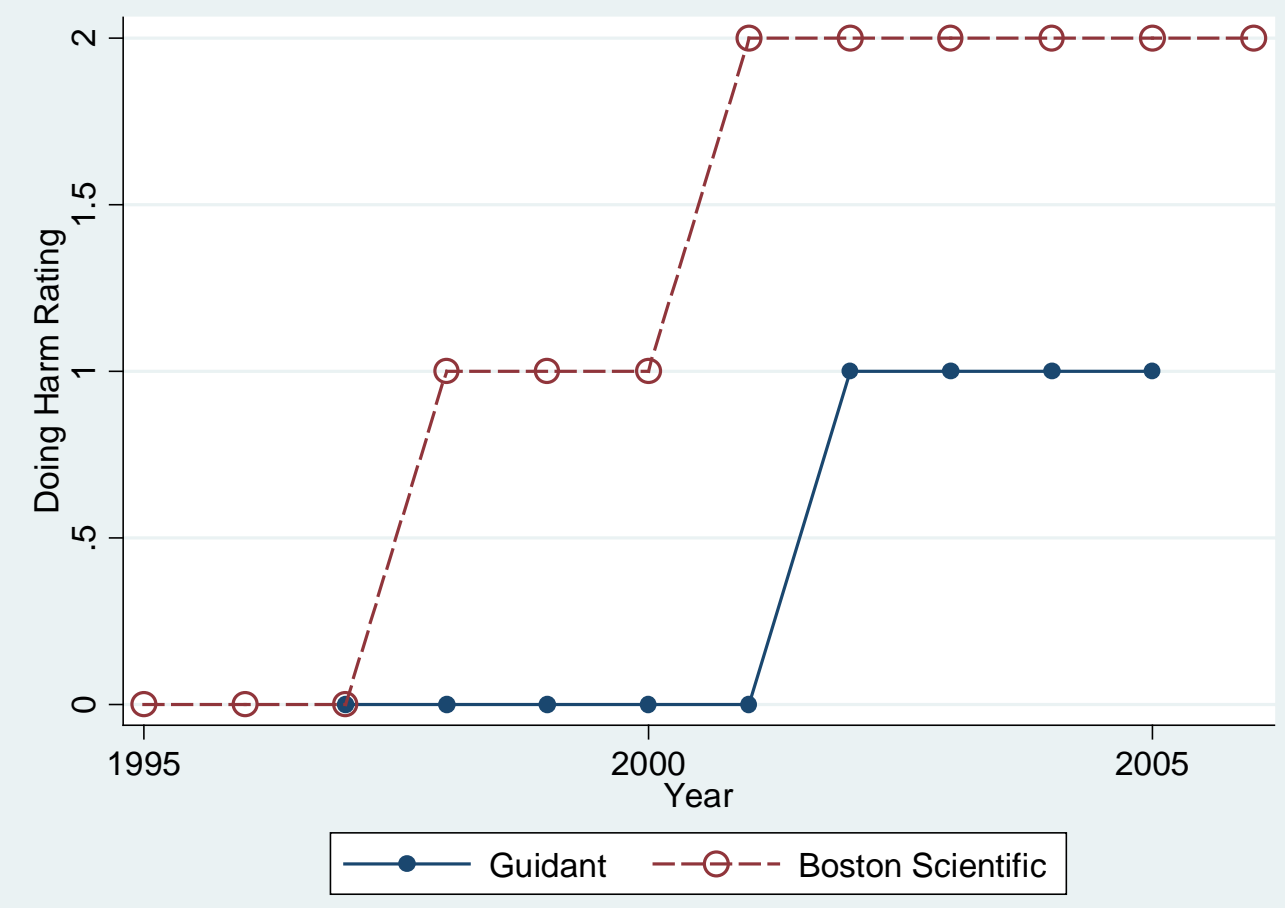

Figure 2: Doing Harm Rating Over Time of Guidant and Boston Scientific

Source: KLD 


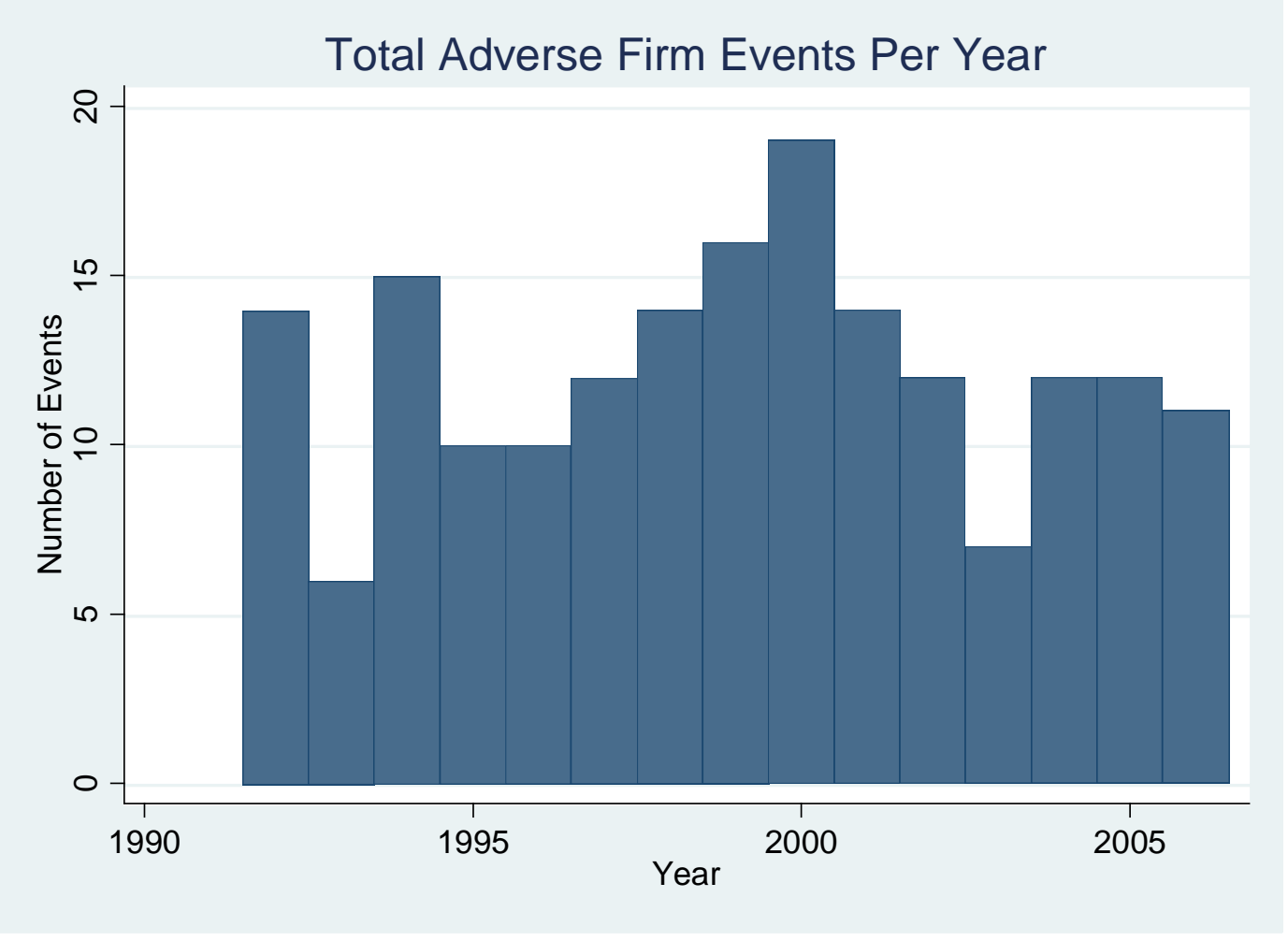

Figure 3: Annual Incidence of Product Recall Events

Source: KLD 


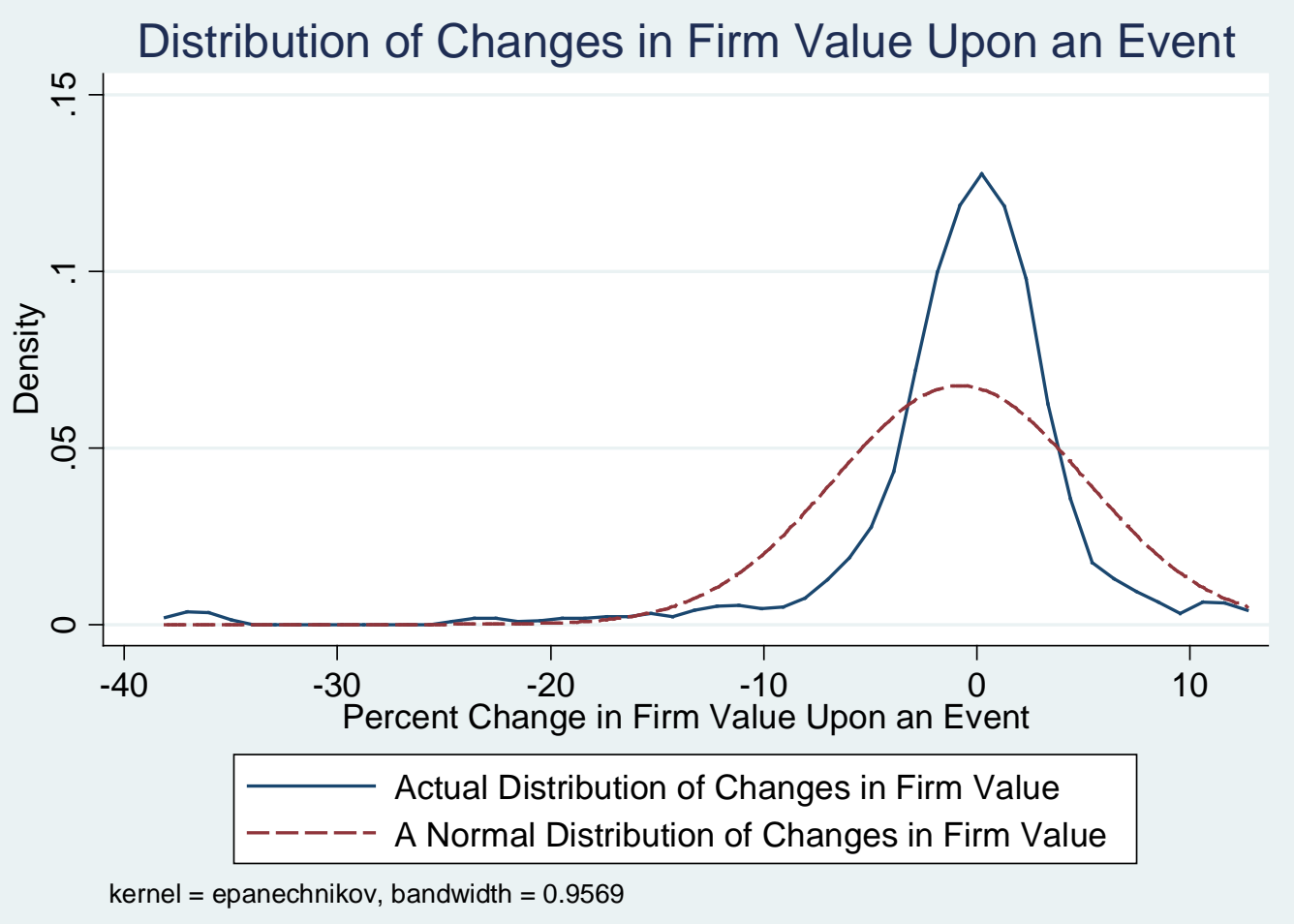

Figure 4: Plotting the Frequency of Different Changes in Firm Value Upon an Event Source: KLD 


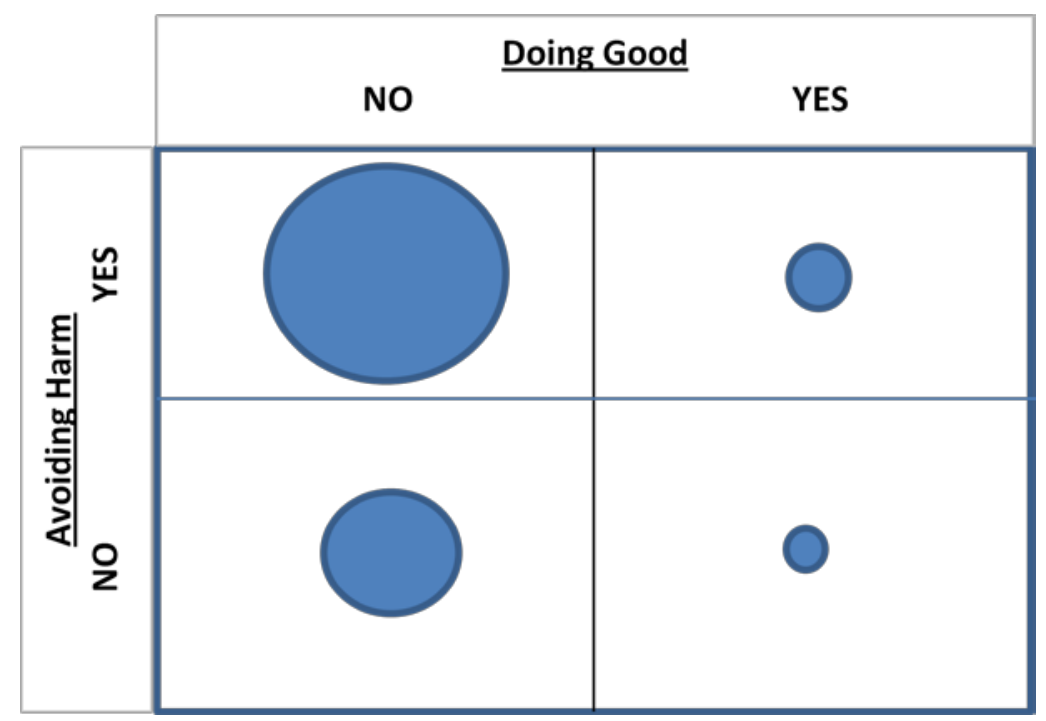

Figure 5: The Amount of Firms of each Quadrant Type having Events Source: Wall Street Journal and KLD 


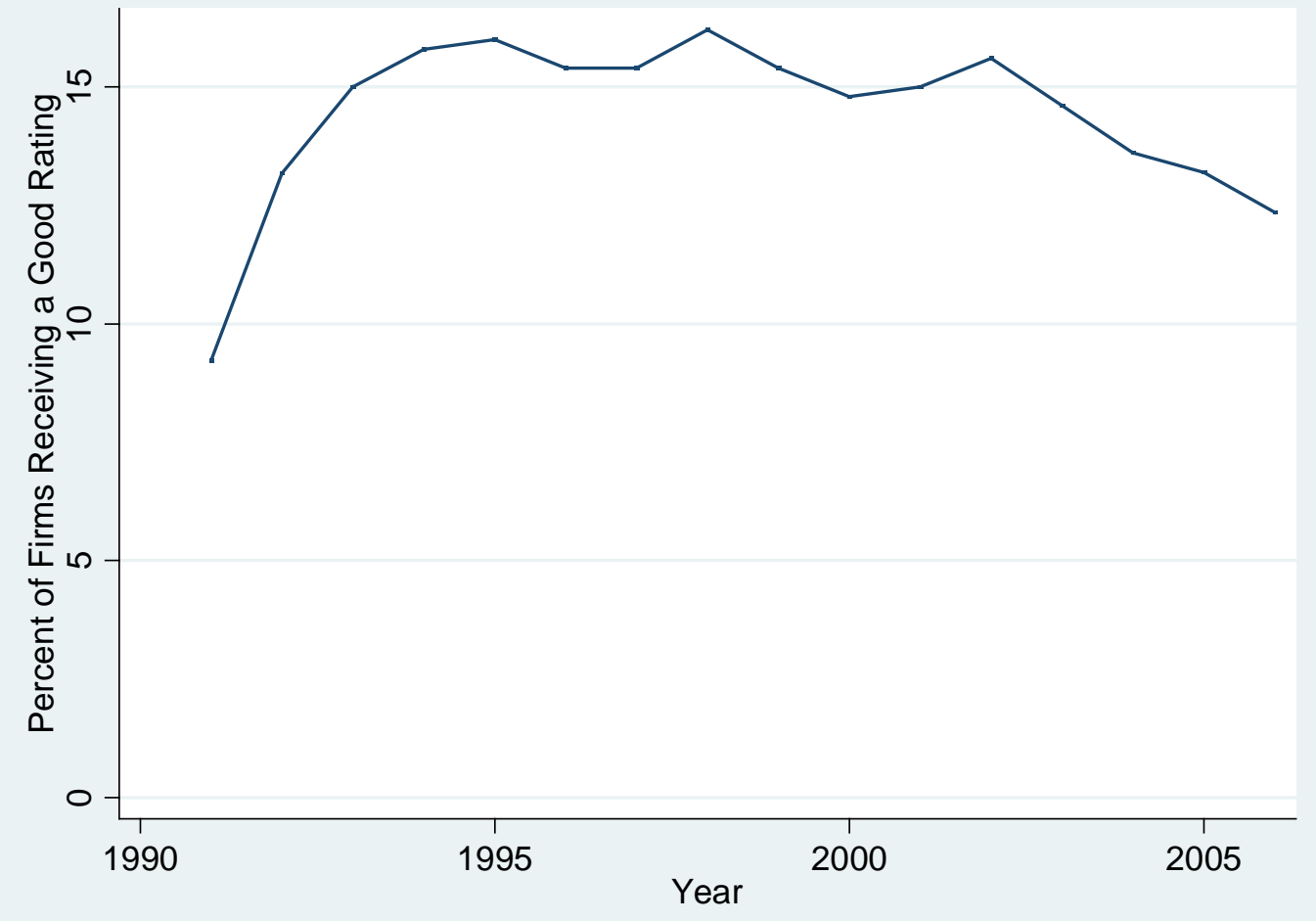

Figure 6: Percentage of Firms Receiving a Rating for Doing Good

Source: KLD 


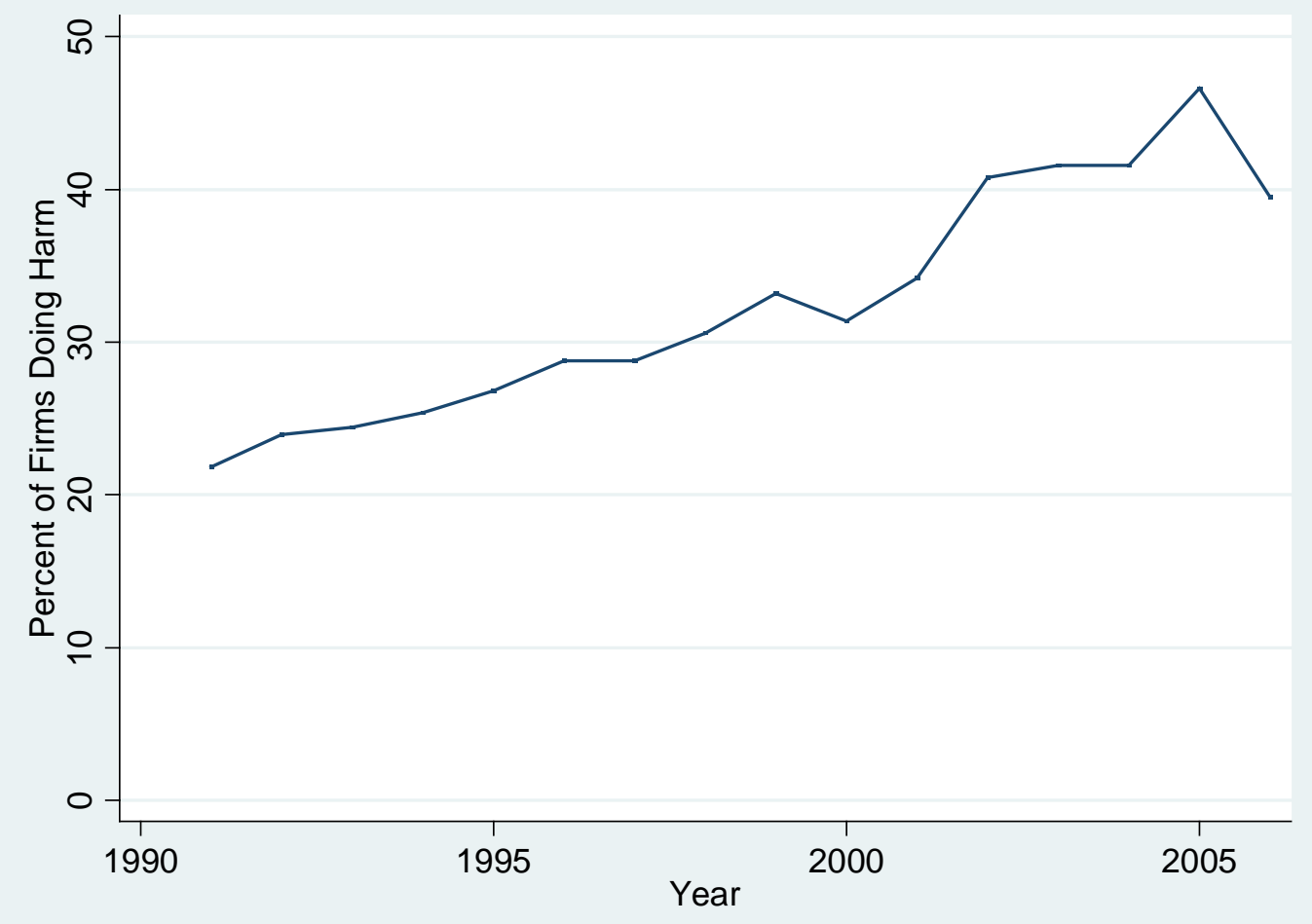

Figure 7: Percentage of Firms Receiving a Rating for Doing Harm

Source: KLD 


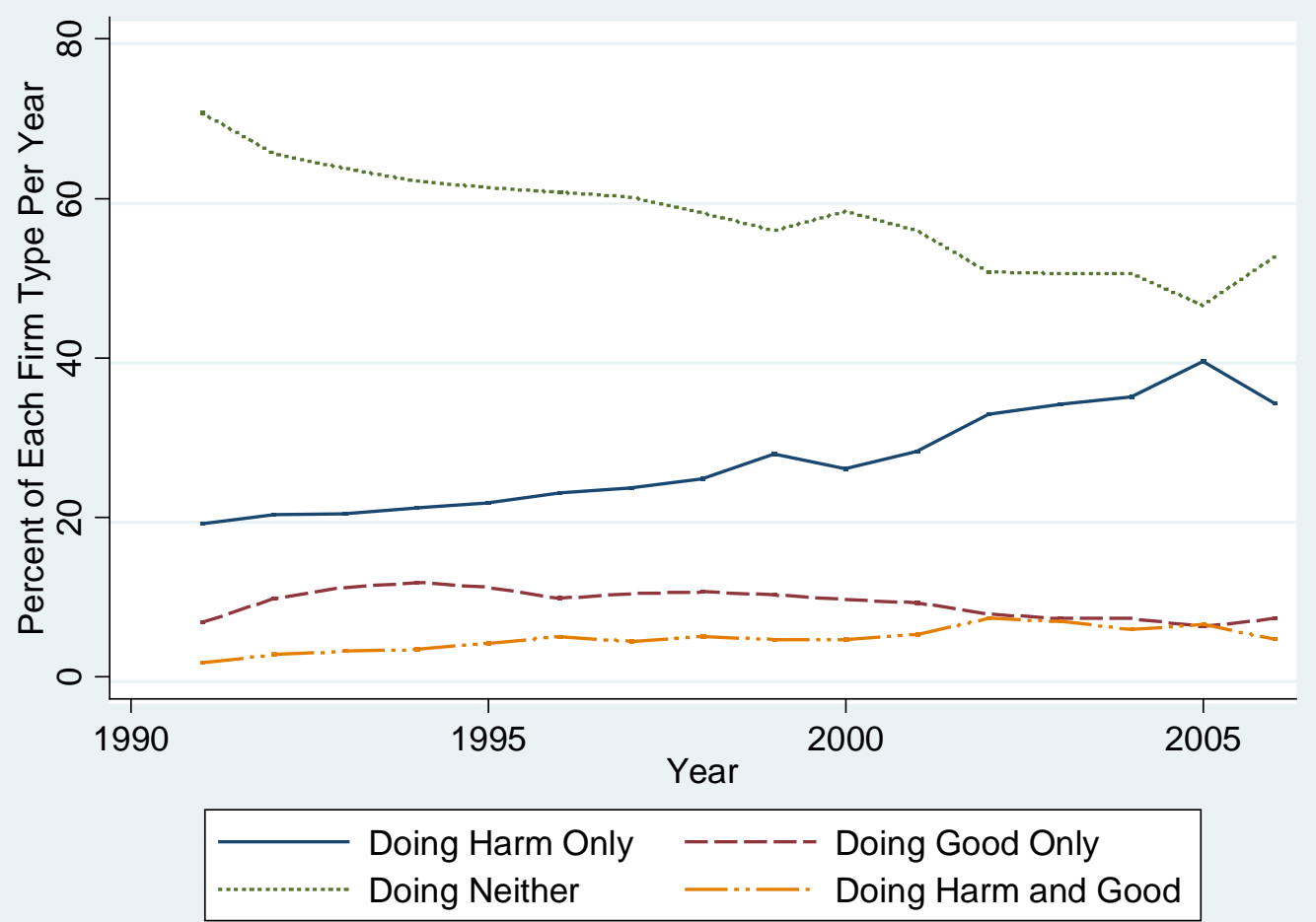

Figure 8: Percentage of Firms of Each Type Over Time

Source: KLD 


\begin{tabular}{|c|c|c|c|}
\hline $\begin{array}{c}\text { CSR Reputation } \\
\text { Type }\end{array}$ & $\begin{array}{c}\text { Number of } \\
\text { Observations }\end{array}$ & $\begin{array}{c}\text { Mean } \\
\text { Return }\end{array}$ & $\begin{array}{c}\text { Standard } \\
\text { Deviation }\end{array}$ \\
\hline Doing Good Only & 19 & $1.10 \%$ & $2.97 \%$ \\
\hline Doing Neither & 55 & $-0.50 \%$ & $4.63 \%$ \\
\hline Doing Harm Only & 83 & $-0.90 \%$ & $5.86 \%$ \\
\hline Doing Harm and Good & 27 & $-2.51 \%$ & $8.97 \%$ \\
\hline All Types & 184 & $-0.80 \%$ & $5.90 \%$ \\
\hline
\end{tabular}

Table 1: Abnormal Change in Firm Value upon an Event per Each CSR Type

Source: CRSP, KLD, and Wall Street Journal 
1 “Toyota recalls will cost owners in lower resale values." USA Today. (February $5^{\text {th }}, 2010$ )

${ }^{2}$ Mark A. Stein. "Paying the Price When Companies Stumble" New York Times. (September $16^{\text {th }}, 2006$ )

${ }^{3}$ Stephen Shankland. "Google Unlocks Once Secret Server" CNET. (April $\left.{ }^{\text {st }}, 2010\right)$

${ }^{4}$ Louise Story and David Barboza. "Mattel Recalls 19 Million Toys Sent from China." The New York Times. (August $\left.15^{\text {th }}, 2007\right)$

${ }^{5}$ For a thorough study and meta-analysis see Margolis, J. D., Elfenbein, H. A., \& Walsh, J. P. (2009). “Does it pay to be good...and does it matter? A meta-analysis of the relationship between corporate social and financial performance." Working Paper. Harvard Business School, Harvard University, Boston, MA.

${ }^{6}$ Aaron Chatterji, David I. Levine, and Michael W. Toffel. "How Well Do Social Ratings Actually Measure Corporate Social Responsibility?" Working Paper 07-051 (2009). Harvard Business School, Harvard University, Boston, MA

${ }^{7}$ Since KLD CSR ratings are retrospective (they are based on activities over the previous calendar year), we report a firm's year t's current rating using KLD data from year $t+1$.

${ }^{8}$ Abnormal return is measured via a financial event study. A financial event study simply determines the deviation of a firm's market return from its expected return during a given market environment.

${ }^{9}$ See David Vogel (2005) for a review of different rationale of CSR and its empirical validity. David Vogel, The Market for Virtue (Washington DC: Brookings Institution Press, 2005) 